\title{
"It's the First Time I Feel as One". Patients' Experience of Therapeutic Body Wraps in Swiss Public Adult Inpatient Psychiatric Wards
}

\author{
Krzysztof Skuza ${ }^{\mathrm{b}, *}$, Julie Dubois ${ }^{\mathrm{a}}$, Gilles Bangerter ${ }^{\mathrm{b}}$ \\ ${ }^{a}$ Foundation of Nant Psychiatric Hospital, Corsier-sur-Vevey, Switzerland \\ ${ }^{\mathrm{b}}$ HESAV School of Health Sciences, University of Applied Arts and Sciences of Western Switzerland, Av. de Beaumont 21, 1011 Lausanne, Switzerland
}

\section{A R T I C L E I N F O}

\section{Article history:}

Received 14 February 2017

Revised 22 March 2017

Accepted 9 April 2017

\section{KEYWORDS:}

Patient experience

Anxiety

Complementary therapies

Narratives

Psychosis

\begin{abstract}
A B S T R A C T
Many patients suffering from serious mental illness experience severe anxiety, and those with psychosis often report feeling that their bodies are falling apart. Expert opinions reported relational benefits and tranquilizing effects of therapeutic body wraps (TBWs). Yet this adjunct nursing therapy has rarely been studied and the existing knowledge is limited to single clinical cases reported from clinicians' perspectives. This study reports on seven adult patients, whose independent accounts of TBWs were audio-recorded, transcribed and cross-analyzed. It sheds light on a commonly underestimated need among many severely ill psychiatric patients to have their anxiety addressed on a bodily level.
\end{abstract}

(c) 2017 Elsevier Inc. All rights reserved.

\section{INTRODUCTION}

Therapeutic body wraps (TBWs) (Woodbury \& Woodbury, 1998; Woodbury et al., n.d.), also referred to as cold wet sheet packs (Silver, 1986, 1992; Ross et al., 1988; Puskar et al., 1990) and packing therapy (Cohen et al., 2009; Consoli et al., 2010), are a nursing psycho-body approach to address clinical issues of anxiety in severely ill psychiatric inand out-patients.

The general clinical rationale of the use of TBWs in Switzerland originally draws from psychodynamic concepts, such as holding and handling (Winnicott 1955, 1965; Winnicott et al., 1989), containment (Bion, 1963) and psychic skin (Bick, 1968).

The nursing clinical rationale of the use of TBWs draws from interpersonal theory of Peplau (1952/1991) and the milieu theory of Gunderson (1978). In reference to the earlier theory, TBWs are regarded by nurses as a clinical setting for initiating privileged interpersonal therapeutic relationship already during the acute phase of psychiatric illness. It is achieved through the nurses' supportive and receptive presence that accompany the patient during his experience of bodily sensations and associated psychological states while in the TBW. The latter theory by Gunderson and his concept of the five-fold therapeutic milieu is of special interest for psychiatric nurses who are in charge of creating and maintaining such a milieu (Thomas et al., 2002). TBWs appear to be one of therapeutic tools at nurse's hands to materialize the

\footnotetext{
* Corresponding author.

E-mail addresses: k.skuza@hesav.ch (K. Skuza), julie.dubois@chuv.ch (J. Dubois), gilles.bangerter@hesav.ch (G. Bangerter).
}

Gunderson's concept of containment both on the relational (two-onone or one-on-one relationship) and physical level (tight sheets). As noted by Ross (1988) and Puskar et al. (1990), TBWs offer a containment that is associated with the feeling of security and are effective in reducing levels of anxiety.

However, a recent alternative and complementary rationale for body wraps is provided by the sensory integration approach as described by Ayres \& Robbins (2005) and Kloeckner et al. (2009). The latter insists on 'the hierarchical organization of the somatic sensations that serve as foundations for the individual's perceptions, behaviours and learning' (Consoli et al., 2010). The sensory integration approach replaces the earlier psychoanalytic concept of disintegration with the concept of severe sensory integration dysfunction and body maps disorganization (Cohen et al., 2009), clinically associated with catatonia in the context of schizophrenia or pervasive developmental disorder. Historically, the therapeutic use of TBWs in Switzerland is linked to the person of Michael Woodbury, an American psychiatrist and psychoanalyst, who brought TBWs from the famous Chestnut Lodge in Rockville, MD to Prangins on the shore of Lake of Geneva in the 1960s. It is noteworthy that Hildegard Peplau did a training internship at Chestnut Lodge between 1941 and1942 under the supervision of Frieda Fromm-Reichmann, where she practiced TBWs with hospital's inpatients. From Prangins, the TBWs rapidly spread to the entire French speaking part of Switzerland but interestingly enough never made it to the clinics in the German speaking part of the country. The clinical use of TBWs nowadays, albeit relatively restricted due to a range of administrative reasons, is both reminiscent of Chestnut Lodge, where Frieda Fromm-Reichmann used them as a setting for her therapeutic sessions with agitated patients 
(Hornstein, 2000; see also Silver, 1992 for a case report of treatment of her borderline patient) and fully integrates latest scientific references, namely the sensory integration theory.

The patient's entire body, except the face area, is tightly wrapped in wet cold sheets (below $60{ }^{\circ} \mathrm{F} / 15^{\circ} \mathrm{C}$ ) and covered by blankets. As documented by Opsommer et al. (2016), TBW clinical teams are composed mostly by two psychiatric nurses, a nurse and a psychiatrist and, less frequently, by any of the latter two and a clinical psychologist. Two clinicians take seats on either side of the patient's bed, should the patient wish to communicate. A procedure of sensory stimulation consisting of simultaneous and symmetric soft pressure on the patient's body by the nurses can be added to manage sensory integration issues. The patient's limbs and joints are pressed through the wrap, beginning with the toes and up to the head. Each pressure is simultaneously verbalized by one of the nurses, who names aloud the part of the body being touched and so doing narratively reconstructs the continuity of the patient's body: "this is your knee that is linked with your thigh". Bodily limits are marked by one nurse pressing the patient's head softly as the other nurse gently pushes the feet.

The physiological process of rapid subcutaneous vasoconstriction and vasodilation is believed, in addition to a cenesthesic holding action of tight sheets, to confer a better consciousness of the bodily limits and has been suggested to have an anxiolytic and sedative action on manic symptomatology as expressed by psychomotor agitation (Baruch, 1903; Black, 1936; Wright, 1940; Kilgalen, 1972; Ross et al., 1988; McAfee, 1989; Woodbury \& Woodbury Farina, 1998; Silver, 2000). Confirming findings of these earlier studies, Consoli et al. (2010) reported that developing (adolescent) individuals usually sleep during the warm time of the session. However, despite the suggestion of Ross et al. (1988) that physiological effects of wraps be studied in healthy volunteers, no such study was conducted so far. Recently, Consoli et al. (2010) reported that the adolescent individuals in their sample usually fell asleep once the wrap warmed up. A recent investigation suggested a potential statistical correlation between TBWs and the use of anxiolytics and neuroleptics in adult inpatients (Opsommer et al., 2016).

Despite some first-person accounts, such as Joanne Greenberg's (McAfee, 1989; Green, 1964), and single-case studies (de Coulon \& Müller, 1981; de Coulon, 1985; Ross et al., 1988), to our knowledge, there is currently no systematic qualitative approach to adult patients' experience of TBWs, as there is little empirical examination of psychiatric patients' experience in general (Thomas et al., 2002). However, a recent multiple case study of TBWs in adolescent patients with schizophrenia included some experiential first-hand material (Cohen et al., 2009).

The present paper reports on a multiple-case study that accompanied our recent retrospective cohort study (Opsommer et al., 2016) and aimed at providing the first elements to fill the gap due to the lack of data on TBW use for this population.

\section{METHOD}

The experiences of seven ex-psychiatric patients/outpatients with TBWs were explored using semi-directive interviews. The subjects were recruited through the intermediary of the clinical staff of two public psychiatric hospitals in the French-speaking part of Switzerland. The research complied with the national standards of ethics and was approved by ethics committees in the Swiss cantons of Vaud (CERVD36/13) and Valais (CCVEM 026/13). The subjects were identified during their inpatient admission or shortly after discharge. The clinical staff informed the subjects about the study and obtained their tentative consent to have their contact details transferred to the researchers. The researchers then contacted the subjects and arranged for an interview at a place of their choice. The subjects were subsequently provided with full information on the study and signed a formal consent sheet.

The main inclusion criterion was having experienced TBWs during a stay at an inpatient adult (18-65 years of age) hospital that dated back one to three months before the interview. This time frame was set to collect accounts of TBWs experiences that would not be modified by an excessive amount of elapsed time between the bodily experience of TBWs and its verbal restitution or prematurely expose patients to memories of the psychiatric episode. Other inclusion criteria were the capacity of informed consent and the capacity to understand and speak French. The exclusion criteria were the presence of dementia, mental retardation and a history of other psycho-body therapeutic approaches, such as physiotherapy, massage and baths. Seven subjects were included in the study (five females and two males, aged 21 to 54). Three subjects had experienced TBWs with afferent "stimulation", three subjects had experienced TBWs without additional stimulation, and one had experienced both. The study initially aimed at including ten subjects, however this proved not feasible for several reasons. Only few patients are currently offered TBWs during their inpatient hospitalization. This is due to the fact that the inpatient stays are presently very limited in time and that the therapeutic teams are reluctant to initiate psychobody approaches that are deemed incompatible with short stays and time consuming for the hospital clinical staff. A quantitative inquiry (Opsommer et al., 2016) showed that TBWs are mainly offered to patients diagnosed either with any of the DSM IV TR diagnostic categories within F20-29 or F30-39 groups, which makes them a potentially difficult target group to include in a study directly following an inward episode. Three persons initially agreed to be interviewed and eventually declined when contacted by the interviewer after the discharge from hospital. One more person that initially agreed was readmitted to an inpatient ward before the interview could take place. Finally, in order to minimize any negative impact on participants, an approval by relevant clinicians was regularly sought before each participant was approached. An interplay of the above reasons arguably made it for the inclusion of seven subjects instead of ten within the duration of the study (15 months).

The interviews were conducted in French by single female interviewer blind to the interviewees' diagnoses. She met the subjects at their homes (6) or at a public coffee shop (1), according to their stated preference. To obtain an implicit understanding that eventually proved crucial for the subsequent analysis, the interviewer was wrapped in both participating hospitals, thus ensuring that she would personally experience both wrapping techniques. The interviews lasted between 45 and $120 \mathrm{~min}$ and were integrally audio-recorded, transcribed and anonymized by the interviewer. The integral transcriptions were categorized using an inductive method of emergence of endogenous categories and cross-analyzed.

\section{FINDINGS}

The presentation of the findings follows a typical chronology of a TBW treatment, starting with the clinical staff's TBW offer, followed by the first and subsequent TBWs, and ending with the end of the treatment. Special attention is given to the interviewees' subjective psycho-body experience.

\section{PRESENTATION OF THE WRAPS}

All patients in the sample were offered this treatment on a voluntary basis and were provided descriptive information regarding the technique itself and the clinicians' therapeutic objectives. It is to be noted that for patients admitted for the treatment of anorexia (two patients in our sample), regardless of underlying psychotic comorbidity, the TBWs were part of a wider "therapeutic offering package" that included other techniques, such as mirror therapy, and tended to be explained in less detail to these patients than to other patients. The therapeutic objectives, as recalled by the patients, were mainly "to center oneself on the body" or "to feel better one's body" and "to ease the anxiety". However, most interviewees insisted that the most salient features of TBWs at the very moment they were presented them were not the therapeutic 
objectives but the technique itself in general and the initial cold of the wet sheet in particular. It is noteworthy that three interviewees reported that information on TBWs they received from their fellow patients on the ward was of similar importance to the information provided by the clinical staff. Whereas some interviewees were clearly unsettled by the accounts of the initial cold, others saw the TBWs in terms of an occupational alternative that they viewed as desirable in the context of the perceived boredom of the inpatient ward. Importantly, their peers' accounts played a role in overcoming the first unsettling impression of TBWs. Curiosity and eagerness about an alternative to drugs were also mentioned.

\section{THE FIRST WRAP}

The experience of the first TBW-in a series that can range from a few to several dozen treatments and, in exceptional cases, to as many as 200 treatments-is radically different from all subsequent TBWs in that the very first TBW cannot be anticipated based on previous experience. Many accounts of the first wrap are best analyzed in terms of a combination of an experienced comfort and an original unease related to nudity. In some cases, such an ambivalent or apparently contradictory perception of TBWs lasted from the very first in the series to the last one. In other cases, TBWs appeared to be unproblematic from the beginning. Noticeably, no patient interrupted the treatment.

Various patients expressed their simultaneous perception of clinicians' precautious attitudes and their own feeling of comfort, the latter being induced by the former:

"So I can feel I'm being wrapped up (...) everyone is very careful; they place a little pillow under my head. (...) The first time, it was striking. I felt like kind of purified, as if... I don't know." (Interviewee 2).

"First he explained to me what the wrap was. He told me "We're going to take care of you. You can relax; it's going to be all right". I don't remember what he told me exactly, but broadly speaking, that it was the moment I had to take for myself, that I could put aside all guilt and anxiety because time came to a standstill. That we were just living here and now, with no need to think about before or after. That we were like in an interlude, a bubble, and that I was taken care of. Well, I.....at that time, I was scattered, doubting everything, not knowing where I was going, scared of everything. This very reassuring man told me, "We are taking charge of you; everything is going to be all right". Well, [there were] only reassuring messages like these. It was really a good experience. That's it". (Interviewee 3).

However, the first TBW also inspired some apprehension, and the technique was perceived as at least unusual if not bizarre. Nudity, cold and the difficulty of establishing a link between these two elements and the therapeutic objectives contributed to the necessity of a lengthy process before patients fully adopted TBWs:

"(...) it's hard to have to be naked. Because it feels like as if you are nothing anymore. I mean, when you are wrapped in this ice-cold sheet... well, you feel like you don't belong to yourself anymore, that you are left to the nurses. And, well, at the beginning, I thought: "This thing is really nuts". They would tell me: "Focus on your body sensations". And I was like, "Yeah, right, I already feel like a sausage, and on top of that, it's cold" (laughter). Anyway, it took me quite some time to get fully into it, to understand it, to let go (...) because it felt so insane. And I said to myself, "This is some prehistoric stuff!" (Interviewee 5).

"What bothered me was to... well, yeah, it was this cold first, and then, I think, to stay still like that, I don't like it much doing nothing. And during the first wrap, they do nothing either. So I just stayed lying like that, and at the same time, I couldn't understand really well what it meant. Where it would end up. So it was a bit hard. I don't know if it's that first impression that remained." (Interviewee 6).

ENTERING INTO THE WRAP SERIES: GIVING IT A MEANING AND LETTING GO

Among interviewees who were particularly stuck by the perceived awkwardness of TBWs, the experience of the first TBW was insufficient to overcome their initial reserved attitude towards the technique. Thus, several TBWs were necessary before they could fully "enter into the wraps", i.e., manage to feel at ease.

Interviewee 5: "Well, if I'm in a very bad state, I cannot feel anything (laughter). And I think that it's also linked to fact that you have to enter into the process. I mean, to not think "that's the thing the nurses or the doctors wanted, so..." (laughter) (...). You really have to think to yourself, "Yes, I do this" or "Yes, I listen to my body; I try to focus" and so on.

Interviewer: You have to play along with the game?

Interviewee 5: Yes. Because otherwise, if you just endure it, it's like forcing a kid to go to school; he will never get pleasure out of it. I mean, he will never benefit from it the way he would have if he had wanted to go in the first place.

Interviewer: So what changed your mind?

Interviewee 5: I saw that it's done me good. Because at first, it seemed really barbaric to me. I told myself, "Oh right, it's true that psychiatry is barbaric. I was told so, but..." (laughter).

The perceived subjective beneficial effects of TBWs often appeared to be the turning point and eventually did outweigh patients' apprehension towards and dislike of TBWs. Simultaneously, the growing confidence in the clinicians, the emergence of a meaning and a sense of being an active part of the process contributed to the interviewees' appropriation of the technique.

\section{PSYCHO-BODY EXPERIENCE}

The following categories were constructed on the basis of TBWs' most salient features, as stated by the patients during the interviews. These are not either/or categories; they often coexist within many single accounts.

\section{a. ANXIOLYSIS/PROTECTION}

Anxiolysis was frequently the therapeutic goal of the TBWs, as mentioned by the clinicians and explicitly stated in patients' medical records, particularly among patients whose symptoms included manic defenses against anxiety. The therapists' idea of slowing down patients' pace and bracketing off their manic preoccupations by creating a safe and containing time-space bubble was reflected in some patients' accounts. They frequently portrayed the TBWs as "mind-quieting" (Interviewee 5), as providing an "impression of calm" (Interviewee 2) or, as shown in the excerpt below, as a very welcome break in the midst of a manic episode:

"[The wrap] is a moment where all your guilt, all the hyperactivity in your brain is kind of paused. I said to myself: "Ok, it is what it is, and I have no control over it. I'm here now. I'm not in a threatening environment; I'm surrounded by friendly people who don't want to harm me. Here, I can breathe; I can relax". And it was one of the only moments in weeks where I said to myself: "Stop. Now, I'm here. I'm here, and I don't have to pay my bills anymore, I don't have to pick up distressing phone calls. I don't have to cope with things, to run and to drown. There's no more weight on my shoulders, no more responsibilities, no more... well, I can let myself go, and other people will take over because I can't anymore." (Interviewee 3)

\section{b. BODY LIMITS AND BEING ONE}

Similar to anxiolysis, body-limit restoration and/or the reintegration of the experience of the body and its image are among the main therapeutic goals of TBW, as evidenced in many interviewees' accounts. In particular, the capacity to invest one's entire body instead of existing solely "within my head" (Interviewee 4) was repeatedly mentioned. The body limits experienced during the TBW were described as follows by one of the interviewees:

"But otherwise what I felt, yeah, exactly, at the beginning, yeah, there were zones (of my body) that were really very present, and then, at the end, it was as if I had a more complete body. And then, as a matter of fact, it feels pleasant. And then, as I told you before, most of the time, my awareness was that of the spirit alone, and yet, it was pleasant at some 
point when I realized, when I managed to realize the cold and thus the circumference of the body, in fact. It was rather pleasant, in fact, because it was harmonized (...). I didn't think that my conclusion would be "Yeah, actually, I have to accept that I am within the limits of a body, and I have no choice but to live with it". I thought that it was a question of shape, but in fact, it was (...) even worse than that; it was a question of simply functioning with a body that has limits. And then, it is true that I didn't realize that other than at the end of the wraps. Anyway, it's not by talking to the shrinks or doing anything else that I came to this conclusion." (Interviewee 6).

Regarding the non-integration of the body, there is an obvious relation with the above-described phenomenon of a disembodied and intellectualized self that can be located by patients as exclusively in the head and the (dis-)continuity between the head and the rest of the body. Being "one" presupposes having a self that is not limited to one part of the body and having a body with parts that are held together safely enough to form a single being. Interviewee 2 described how she eventually managed to feel "one" at the end of her TBWs series:

"[The nurses told me] "Come on, one last little wrap, ok?" It was nice (...). I don't know why, but they asked this question: "Now, how do you feel? What happened?" So I said, "Listen, it's the first time that I feel as one. (...) At the limb level. That I am one. And not 456789 10; you can count. You can count every bone in a skeleton, in someone who's alive. You can count everything, you know. And it was one. And a big one. But it could also have been a ten because it was also a big success, in my opinion (ten used to be the top grade in the Swiss schooling system). And I don't know, they expected... maybe other patients said very different things. But in my case, they saw that things were assembling in here too (she points to her head)." (Interviewee 2)

\section{c. HOLDING AND ITS METAPHORS}

A need to be held very tightly was expressed by three interviewees. Strikingly, one of the accounts was reminiscent of Temple Grandin's (1995) first-person account; her need to be held due to her autism led her to invent and construct a special "squeezing" machine that she could use to hold herself very tightly as a homemade means of combating anxiety. Three compelling metaphors were constructed by the Interviewees: the Lettuce (Interviewee 2), the Mummy (Interviewee 5) and the Imprisonment (Interviewee 7).

Interviewee 2: "So the wrap was honestly a privileged moment for me. They take really, really good care of you, and you stay like this for half an hour, I think-a bit mummified, but not too much. But above all, I was reassured by the sheets' tightening strength. I saw the difference because two nurse trainees did the wrap once. (...) they were lovely, two guys, and they did the wrap much, much more....

Interviewer: ... tightly wrapped?

Interviewee 2: No, the exact opposite, basically. And I couldn't feel anything. I was like a lettuce." (Interviewee 2).

"But it feels weird to be clamped, but after a while, it clearly... it's a bit relaxing, too. When it... because the sheet is... like cardboard, right. It's like cardboard, so you really feel like you are encased in cardboard, clamped. After, that it expands a bit; then, you feel less tight, well, yes, tight... less, I don't know how to say that, like a mummy or..." (Interviewee 5).

"Even relaxation chills you out. But wraps even more because it... you are truly imprisoned, and I think the cold... relaxes the... that's why you sometimes put cold on the... where it hurts, on a sprain or something like that. It, it makes you sleepy. And it, it makes you feel comfortable." (Interviewee 7).

\section{RELATIONSHIP}

The issue of the relationship with clinicians appeared to be particularly rich in that there was whole range of dynamic evolution within the relationships. Some patients described the relationship as "difficult" at the beginning of the TBWs series but stated that it gradually improved over the treatment course. However, the opposite was also reported by other interviewees (Interviewee 3, see below), who saw their relationship with their wrapping team become increasingly difficult. A change in TBW modality, among other factors, may have contributed to a deterioration of the quality of their relationship with the nurses, as in the case of Interviewee 3. This interviewee saw her holding (silent) TBWs transform into so-called "elaborative wraps", which implied that she was expected to freely associate and elaborate on her experience and thoughts and thus enter an "unwanted" treatment that she qualified as "psychoanalytic". Interviewee 3 enjoyed her TBWs only as long as they were limited to a setting that merely offered her an opportunity to be "alone in the presence of another" (Winnicott, 1965).

"I therefore preferred by far those TBWs where nobody expected anything from me; I was at most supposed to slide in. (...) I couldn't move. I could simply let go (...)".

The silent and "holding" relationship she had enjoyed was then replaced by a relationship that she experienced as both intrusive and pointless:

"In this more psychoanalytic approach, I was meant to talk about my childhood, my family, many things I feel had nothing to do with my problems here and now, like what I should do with my employer and things like that."

In cases where the relationship was deemed otherwise unproblematic, intimacy in general and nudity in particular appeared to play important roles (see Interviewee 5 below). Being able to be naked in presence of another was reported in a somewhat paradoxical way as "violent" but as having a durable positive effect on trust in this relationship:

“(...) so I gained confidence in them step by step. I let them see me naked even though I think they don't watch you when they wrap you up, but still, it's something I am not at ease with in general. (...) so knowing them better helped me to gain confidence because it is true that it touches on the intimate sphere of life. (...) this straightened, a bit, the relationship in the sense that it's a moment when they are there exclusively for me and that the three of us share. It isn't like sitting on a couch in front of the shrink and the nurse." (Interviewee 5).

\section{DISCUSSION}

It is our conviction that the clinical richness of patients' accounts is almost inevitably out of the reach of a discussion thereof in terms of mere "results" of the present study. Yet, it is of particular interest to highlight the way our data brought forward a very distinctive feature of TBWs, namely their potential to function like a footbridge over the profound ditch stretching between fundamental, pre-verbal forms of ontological anxiety and usual verbal psychotherapeutic treatments. An alternative metaphor is provided by the French phenomenological psychiatrist Arthur Tatossian (1992) who considers the way TBWs are related to psychotherapy as similar to mordanting the tissue before it can be deep-dyed. In other words, the relationship between up-thestream phenomena leading to severe anxiety, TBWs' reunifying and thus tranquilizing effect and, down-the-stream common forms of psychotherapeutic conversations, is sequential. In order to better understand the nature of this relationship, we are obliged to revisit several core phenomena the experience thereof - by the subject - triggers severe anxiety. All interviewees in our sample reported an experience of one or more of those ontologically threatening core phenomena and linked their remission to their TBWs' experience.

The account of TBWs experience quoted in point 3 ("If I' $m$ in a very bad state, I cannot feel anything") is strikingly reminiscent of the phenomenon described by Minkowski (2002) in his phenomenological account of adult schizophrenia. Minkowski's description draws from Bergson's (1911) fundamental antinomy of instinct and intelligence. For Bergson, instinct is bound to the dynamic and experienced or lived time aspects of reality, whereas intelligence is related to the static, spatial and organized aspects. Minkowski (op.cit., pp. 111-113) remarks that there is a fundamental loss of the dynamic instinct and of the élan 
vital in persons with schizophrenia, whose intelligence is no longer contained or mastered by the salutary simplicity of infra-verbal evidence in the lived life. Orphaned, disembodied and morbid intelligence tries in vain to substitute itself for the gone instinct, which used to make it possible for the person to live in real time instead of being merely capable of thinking it. ${ }^{1}$

As Bergson (1911, p. 49) puts it in "Creative evolution": "We do not think real time but we live it" (italics in original text).

However, the intelligence that allows for thinking is doomed to fail whenever its mission is to replace lived experience. Interviewee 5 reported her inability to feel while she was in an acute state; this feeling was reported by Searles as "pervasive" (1989, p.293) also in persons with borderline personality disorder. As in the case of patients with schizophrenia reported by Minkowski, she resorted to her thinking ability, which remained presumably intact, to reach out for her lived body experience. Remarkably, she eventually succeeded in regaining her capacity to feel through seeing the effects of TBWs on her body. The semantics of her account revealed a subtle change in mode from thought ("you have to think to yourself") to perception ("I saw it's done me good")-that is, from concept to body.

Another compelling example of the proximity between classical theoretical concepts and subjective experience was provided by one interviewee's account of TBWs as an opportunity to be relieved from excessively overwhelming duties ("I can let myself go, and other people will take over because I can't anymore"; see point 4a above). TBWs seemed to represent for this interviewee an opportunity to benefit from a holding environment that made it possible for her to regress to dependence (Winnicott, 1955) in a situation where the objective reality, or her subjective manic apprehension of it, seemed to be beyond her capacity to handle it by herself. Notably, by her own admission, this interviewee categorized her psychic state as "regressed" and compared the TBWs to a "cradle". She also said that she benefited optimally from TBWs in this initial state of regression. However, as she started feeling better and was again able to manage her life, she experienced this setting as way too "mothering" and expressed her dissatisfaction with it. This change was illustrative of the return to independence, as described by Winnicott (1965) in terms of the "towards independence" stage.

The experience of TBWs seemed to be, for some patients, intrinsically bound to the dynamics of regression to dependence and the subsequent return to independence. We believe that these dynamics signal the importance of the pre-verbal and more generally archaic experiences of the self, as illustrated by our data. The account of Interviewee 6 (see point 4b above) was highly evocative of a profoundly disturbed ontology of the self that had lost, to a great extent (if not integrally), the most basic certainty of the "pre-reflective sense of self"; this is known in the phenomenological literature as the ipseity (Latin: ipse $=$ self, itself) and corresponds to a "pre-reflective embeddedness in the world" (Parnas, Bovet \& Zahavi, 2002, p.133). It was a highly significant characteristic of Interviewee's 6 account that an effort had to be made to "manage to realize the cold", which is particularly striking in the case of TBWs. Indeed, the intensity of the initial cold, though short when compared to the duration of a TBW, is not far from the commonly accepted threshold of pain. Here, we are confronted yet again with the phenomenon described by Minkowski (2002), who insists on the extreme difficulty of the schizophrenic to live an experience and not merely to think it. In his example, Minkowski (2002, p. 301) reports the case of a female patient who was impulsively driven to seriously burn herself by setting her clothes on fire in search for a perceptual experience of which she was deprived by her illness. Again, as in the case of Interviewee's 5 inability to feel (point 3), Interviewee's 6 account provided a good illustration of an inevitable failure common to both Minkowski's concept of thinking (that is unable to replace experience) and Winnicott's "thinking as a mother substitute". As Interviewee 6 put it, it was not because of "talking to the shrinks", or, in other words, through verbalization and/or intellect that she gained an understanding of her body-limit issue and eventually managed to have an embodied experience. Being able to positively invest the entire body instead of solely the head can be interpreted in terms of Winnicott's (1973, p. 370) definition of suffering, which includes, among other things, the phenomenon of the loss of contact with the body. The issue of holding brought about an interesting and counter-intuitive use of metaphors by the interviewees, who transformed their ordinary negative meanings into something that was not only positive but also actively sought after. While the Mummy indicated a positive state, the Lettuce described the absence of the beneficial effect of holding for which the interviewee had hoped. Most strikingly, the metaphor of imprisonment as a positive state (Interviewee 7) unveiled a potentially problematic universal status of certain fundamental values (such as liberty/freedom) and their subjective meaning within and outside of psychotic experience. Thus, the very same TBWs seen from the outside as limiting freedom/liberty can be very far from the "protective/calming" TBWs experienced from within. Interpretive priority should be given to the lived TBWs.

From of the angle of interpersonal relation, TBWs seemed to best address the need for non-verbal relatedness. This finding is coherent with the abovementioned pre-reflective being and pre-verbal nature of anxiety associated with such a being. In cases where the psychopathology reveals a fracture of the pre-reflective sense of self and is clinically expressed by primitive agonies, TBWs appear to be an infra-verbal mode of relatedness. Notably, the intrusion of verbalization-regardless of the presumably good intentions of caregivers, who generally rely on it considerably-can prove counterproductive and lead to a premature end of therapeutic alliance, as illustrated by Interviewee 5 . The proportion of pre-verbal and verbal needs is highly varied across patients, so automatic inclusion of the verbal mode of relatedness in the TBW setting may render inadequate any standardized approach to TBWs. It appears, then, that for those patients who are first offered holding TBWs and whose clinicians feel that more verbal elaboration would be helpful, extra care should be taken not to underestimate those patients' pre-verbal needs. Thus, a form of psychotherapeutic conversation, especially if demanded by the patient, could then be carefully explored by the patient and the clinicians and possibly evolve, at least in some cases, into a classical psychotherapy at a later stage.

\section{LIMITS}

The main limitation of this study is its small number of participants. Our sample thus possibly suffers from several biases. The recruitment procedure and a strong reliance on the clinical staff resulted in a sample that might have been biased towards including individuals who were deferential to clinicians and/or their authority. This hypothesis is strengthened by the fact that three persons initially gave their consent to be interviewed while still hospitalized and subsequently declined to meet the interviewer once they were discharged into community. Moreover, the interviewees in the sample were eager to have their stories told and listened to, which could have resulted an overrepresentation of possibly narcissistic personalities. Nevertheless, from the angle of psychopathology, our sample included both persons with minimal residual symptoms and persons presenting significant signs of residual illness.

Finally, only one person in the sample eventually experienced the transition from holding to elaborative TBWs. Her experience of it was negative; however, this should be further explored in a larger sample and cannot be generalized at this point.

\section{CLINICAL IMPLICATIONS}

The added value of TBWs seems to reside primarily in their holding capacity, which addresses pre- and infra-verbal body-related issues. Thus, any introduction of a more verbal therapeutic approach within TBW settings should be preceded by a careful exploration of patients' needs in order to avoid premature verbal psychotherapy. 
In light of the richness of our data, it could prove clinically helpful to involve patients who experienced TBWs in the presentation of the technique to the wrapped-to-be patients. First-person accounts could contribute towards de-dramatizing TBWs.

\section{ACKNOWLEDGMENT}

The authors wish to thank the seven interviewees for their trust and their acceptance to share their experiences of TBWs with us and the readership of this journal. Our gratitude goes also to the nursing and the administrative staff of two participating psychiatric hospitals for their enthusiastic, continuous and devoted support for this study. This study was supported by a research grant from the University of Applied Sciences and Arts Western Switzerland (SAGE-X 35490 and 48786 - K. Skuza).

\section{REFERENCES}

Ayres, A. J., Robbins, J., \& Pediatric Therapy Network (2005). Sensory integration and the child: Understanding hidden sensory challenges. Los Angeles, CA: WPS.

Baruch, S. (1903). The principles and practice of hydrotherapy: A guide to the application of water in disease for students and practitioners of medicine. New York: William Wood and Company.

Bergson, H. (1911). Creative evolution. New York: H. Holt and Company.

Black, N. D. (1936). The value and application of hydrotherapy in a mental hospital. The Psychiatric Quarterly, 10, 34-44.

Bick, E. (1968). The experience of the skin in early object-relations. The International Journal of Psycho-Analysis, 49(2), 484-486.

Bion, W. R. (1963). Elements of psycho-analysis. London: Heinemann.

Cohen, D., Nicolaud, L., Perisse, D., Duverger, L., Jutard, C., Kloeckner, A., ... Danziger, N. (2009). Investigating the use of packing therapy in adolescents with catatonia: A retrospective study. Clinical Neuropsychiatry, 6(1), 29-34.

Consoli, A., Gheorghiev, C. Jutard, C., Bodeau, N., Kloeckner, A., Pitron, V., ... Bonnot, 0. (2010). Lorazepam, fluoxetine and packing therapy in an adolescent with pervasive developmental disorder and catatonia. Journal of Physiology - Paris, 104(6), 309-314.

de Coulon, N., \& Müller, C. (1981). La cure de Packs: Une application des idées de Winnicott en clinique psychiatrique. Lausanne: s.n.

de Coulon, N. (1985). La cure de packs: une application des idées de Winnicott en clinique psychiatrique. L'information psychiatrique., 61, 2.

Grandin, T. (1995). Thinking in pictures: And other reports from my life with autism. New York: Doubleday.

Green, H., \& Greenberg, J. (1964). I never promised you a rose garden. New York: Holt, Rinehart and Winston.

Gunderson, J. G. (1978). Defining the therapeutic processes in psychiatric milieus. Psychiatry, 41(4), 327-335.

Hornstein, G. A. (2000). To redeem one person is to redeem the world: The life of Frieda Fromm-Reichmann. New York: Free Press.

Kilgalen, R. K. (1972). Hydrotherapy-is it all washed up? Journal of Psychiatric Nursing and Mental Health Services, 10, 6.

Kloeckner, A., Jutard, C., Nicoulaud, L., et al. (2009). Intérêt de l'abord sensori-moteur dans les pathologies autistiques sévères I: introduction aux travaux d'André Bullinger. Neuropsychiatr Enf, 57, 154-159.
McAfee, L. L. (1989). Interview with Joanne Greenberg: With three poems by Joanne Greenberg. In A. -L. Silver (Ed.), Psychoanalysis and psychosis (pp. 513-533). Madison: International University Press.

Minkowski, E. (2002). La schizophrénie: Psychopathologie des schizoïdes et des schizophrènes. Paris: Éditions Payot \& Rivages.

Opsommer, E., Dubois, J., Bangerter, G., Panchaud, R., Martin, D., \& Skuza, K. (January 01 2016). Therapeutic body wraps in Swiss public adult acute inpatient wards. A retrospective descriptive cohort study. Journal of Psychiatric and Mental Health Nursing, 23, 207-216.

Parnas, J., Bovet, P., \& Zahavi, D. (2002). Schizophrenic autism: Clinical phenomenology and pathogenetic implications. World Psychiatry: Official Journal of the World Psychiatric Association (wpa), 1(3), 131-136.

Peplau, H. E. (1952/1991). Interpersonal relations in nursing: A conceptual frame of reference for psychodynamic nursing. New York: Springer.

Puskar, K. R., McAdam, D., Burkhart-Morgan, C. E., Isadore, R. B., Grimenstein, J. L., Wilson, S., \& Jarrett, P. (1990). Psychiatric nursing management of medication-free psychotic patients. Archives of Psychiatric Nursing, 4(2), 78-86.

Ross, D. R., Lewin, R., Gold, K., Ghuman, H. S., Rosenblum, B., Salzberg, S., \& Brooks, A. M. (1988). The psychiatric uses of cold wet sheet packs. The American Journal of Psychiatry, 145(2), 242-245.

Searles, H. (1989). Borderline psychopathology as revealed by (a) pauses and (b) ungrammatical word order. In A. -L. S. Silver (Ed.), Psychoanalysis and psychosis (pp. 289-318). Madison, Conn: International Universities Press.

Silver, A. L. (1986). Aspects of abrupt termination: Thoughts on losing my most chronic patient. The Journal of the American Academy of Psychoanalysis, 14(1), 27-45.

Silver, A. S. (1992). Treating the hospitalized borderline patient: Reworking trauma of toddlerhood. The Journal of the American Academy of Psychoanalysis, 20(1), 114-129.

Silver, A. L. (2000). The 2000 Frieda Fromm-Reichmann lecture. The current relevance of Fromm-Reichmann's works. Psychiatry, 63(4), 308-322.

Tatossian, A. (1992). A propos des packs. In T. Albernhe (Ed.), L'enveloppement humide thérapeutique (pp. 294-298). Le Plessis-Robinson: Laboratoires Delagrange/ Synthélabo.

Thomas, S. P., Shattell, M., \& Martin, T. (2002). What's therapeutic about the therapeutic milieu? Archives of Psychiatric Nursing, 16(3), 99-107.

Winnicott, D. W. (1955). Metapsychological and clinical aspects of regression within the psycho-analytical set-up. The International Journal of Psycho-Analysis, 36, 1.

Winnicott, D. W. (1965). The maturational processes and the facilitating environment: Studies in the theory of emotional development. New York: International Universities Press.

Winnicott, D. W. (1973). Delinquency as a sign of hope. In S. C. Feinstein, \& P. L. Giovacchini (Eds.), Developmental and clinical studies (pp. 364-371). New York: Basic Books.

Winnicott, D. W., Winnicott, C., Shepherd, R., et al. (1989). Psycho-Analytic Explorations Cambridge, Mass: Harvard University Press.

Woodbury, M. A., \& Woodbury Farina, M. (1998). The construction of tridemensional representation of body and external reality in man. The greatest achievement of evolution to date implications for virtual reality. In J. D. Westwood (Ed.), Medicine meets virtual reality 19: NextMed (pp. 196-201). Amsterdam: IOS Press.

Woodbury, M.A., Woodbury Farina, M., Bell, R.A. \& Woodbury Farina, M. A. (n.d.). Unpublished report. Cognition and psychosis. The graphic representation cognitive test. The Puerto Rico Institute of Psychiatry, The Puerto Rico Institute of Mental Health, University of Louisville Medical School, University of Puerto Rico Medical School.

Wright, R. (1940). Hydrotherapy in psychiatric hospitals. Boston, Mass: The Tudor Press Inc 